\title{
レーザー吸収分光法を用いた誘導加熱風洞気流診断*1 Diagnostics of Inductively Heated Plasma Generator Flow by Laser Absorption Spectroscopy
}

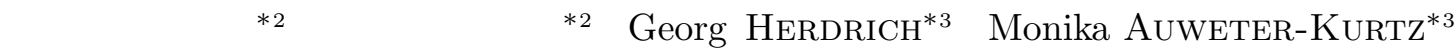 \\ Makoto Matsui, Kimiya Komurasaki, Georg Herdrich and Monika Auweter-Kurtz
}

Key Words : High Enthalpy Flow, Inductively Heated Plasma Generator, Laser Absorption Spectroscopy

\begin{abstract}
Laser absorption spectroscopy was applied to pure oxygen flows generated by an inductively heated plasma generator IPG3. Temporal variation of translational temperature was deduced from measured absorption line broadening of OI $777.19 \mathrm{~nm}$ because the flow properties fluctuated at $300 \mathrm{~Hz}$ in synchronization with the induction current. The specific total enthalpy and mole fraction of oxygen were estimated from the deduced temperature assuming thermochemical equilibrium. Consequently, the averaged degree of dissociation of oxygen is $92 \%$. The specific total enthalpy on the centerline was estimated at $33.7 \pm 2.9 \mathrm{MJ} / \mathrm{kg} ; 43 \%$ of it was in the form of chemical potential. Results show good agreement with intrusive measurements.
\end{abstract}

\section{1. は じめ に}

宇宙往還機や惑星探査機の熱防護システム (Thermal Protection System) の開発には, 地上設備により再突入 環境を模擬する必要がある.このような高エンタルピー気 流を生成するため構造が簡易で作動時間が長いアーク風洞 が広く使われている1 4) . しかしながら近年 , TPS 材の表 面触媒性効果や酸化反応, 実在気体効果などが重要な問題 として認識されつつあり ${ }^{5 \sim 8)}$, 電極溶融による気流の污染 が正確な化学反応定数評価を妨げるものとして深刻な問題 となってきた9,10).

それゆえヨーロッパを中心として誘導加熱風洞が注目を 浴びてきている11 13) . 誘導加熱風洞はコイルにより間接的 にガスを加熱するため，不純物が非常に少なく TPS 試験 には理想的な高エンタルピー気流を生成することができる また電極が気流中にないことで二酸化炭素等の反応性ガス も使用することが可能であり，火星や金星への突入環境を 模擬することができる ${ }^{14)}$. 我が国でも ISTA/JAXA が触 媒性, 実在気体効果試験用として $110 \mathrm{~kW}$ 級プラズマトロ ンを ${ }^{15)}, \mathrm{ISAS} / \mathrm{JAXA}$ が金星大気模擬用として $10 \mathrm{~kW}$ 級 ICP を開発・試験中である ${ }^{16)}$.

本研究ではシュツットガルト大学航空宇宙システム研究 所 (IRS) で開発された誘導加熱風洞 IPG3 (Inductively heated Plasma Generator 3) ${ }^{11,14)}$ 気流の診断を行ったの でとの結果を報告する．

第 1 図に IPG3 の概略図を示す. 本風洞ではマイスナー

\footnotetext{
*1 C 2005 日本航空宇宙学会

平成 16 年 11 月 26 日原稿受理

*2 東京大学大学院新領域創成科学研究科

*3 シュツットガルト大学航空宇宙システム研究所
}

型共振回路を採用しておりコンデンサの電気容量を $6 \mathrm{nF}$ から $42 \mathrm{nF}$ まで変えることでさまざまな作動ガスに対して 高いエネルギー変換効率を達成できる RF 周波数 (0.5〜 $1.5 \mathrm{MHz})$ を選ぶことができる.また本風洞のアノード電 流 $I_{\mathrm{A}}$ は直流電源のリップル $(50 \mathrm{~Hz}, 3$ 相交流を整流した もの) により第 2 図のような特性をもつ. 同図にはフォト ディテクタ (DET $110 \mathrm{M}$, Thorlabs 社製) により検出した プラズマ発光信号も示す.どちらの信号も $300 \mathrm{~Hz}$ 程度で振 動しており，このことは本風洞により生成された気流が定 常でないことを示している。

IRS ではこれまでカロリメータ, ピトー管, マッハプロー ブ, 熱流束プローブなどさまざまな接触測定を用いて IPG3 気流のプラズマ電力, 全圧, マッハ数, 熱流束を測定して きた ${ }^{17,18)}$. 第 $1 ， 2$ 表に光れ光れ IPG3 の作動条件および， これらの計測により得られた物理諸量を示す．しかしなが らプローブ計測では測定時に気流に擾乱を与え, また気流 の空間的, 時間的な物理量の変化を測定することは難しい . そこで本研究では気流中の酸素原子を対象としてレーザー 吸収分光法を適用し, 吸収ラインの拡がりから気流の比エ ンタルピーを推定した。

\section{2. レーザー吸収分光法}

Beer-Lambert の式より吸収係数 $k(\nu)$ はプローブレー ザー強度 $I_{0}$ および透過強度 $I$ と次のような式で関係づけ られる19).

$$
\int k(\nu) \mathrm{d} x=-\ln \left(\frac{I}{I_{0}}\right)
$$

ここで, $\nu$ はレーザー光の振動数,$x$ は光路方向の座標を 表す． 


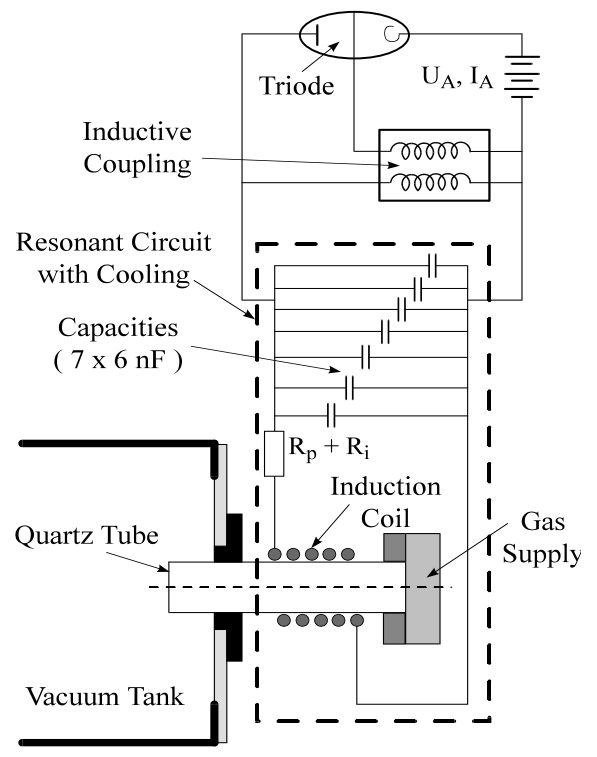

第1図シュツットガルト大学 IPG3

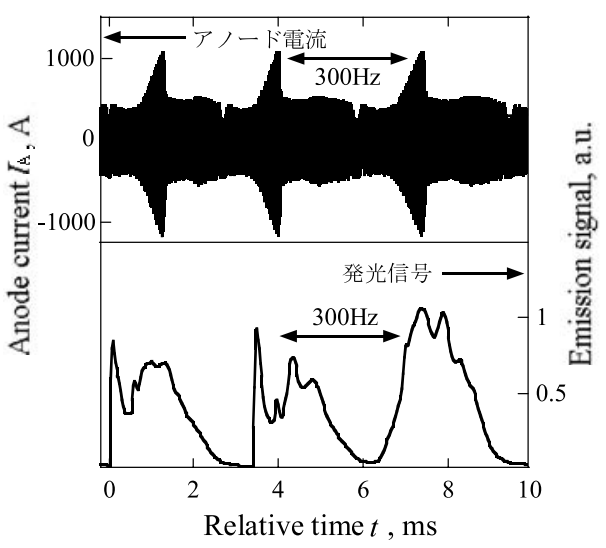

第 2 図 アノード電流およびプラズマ発光信号

第 1 表 作動条件

\begin{tabular}{lc}
\hline \multicolumn{1}{c}{ Operational condition } & Value \\
\hline Working gas & $\mathrm{O}_{2}$ \\
Mass flow $\dot{m}$ & $3 \mathrm{~g} / \mathrm{s}$ \\
Anode power $P_{\text {anode }}$ & $110 \mathrm{~kW}$ \\
Coil turn & 5.5 \\
Number of capacitors & 4 \\
Chamber ambient pressure $p_{\mathrm{amb}}$ & $30 \mathrm{~Pa}$ \\
\hline
\end{tabular}

第 2 表 プローブ計測による測定結果

\begin{tabular}{lc}
\hline \multicolumn{1}{c}{ Parameter } & Value \\
\hline Plasma power $P_{\text {plasma }}$ & $28.2 \mathrm{~kW}$ \\
Total pressure $p_{0}$ & $410 \mathrm{~Pa}$ \\
Mach number $M$ & 3 \\
Heat flux density $\dot{q}$ & $2.1 \mathrm{MW} / \mathrm{m}^{2}$ \\
\hline
\end{tabular}

一方本実験条件下では $k(\nu)$ の拡がりはドップラー拡がり か数 $\mathrm{GHz}$ 程度と他の自然拡がり, 衝突拡がり, シュタルク 拡がり等に比べ 2 椼以上大きい.よって $k(\nu)$ は以下のガ ウス分布で表せる20).

$$
k(\nu)=\frac{2 K}{\Delta \nu_{\mathrm{D}}} \sqrt{\frac{\ln 2}{\pi}} \exp \left[-\ln 2\left\{\frac{2\left(\nu-\nu_{0}\right)}{\Delta \nu_{\mathrm{D}}}\right\}^{2}\right]
$$

ここで $\nu_{0}, K$ は吸収中心振動数，積分吸収係数である. $\Delta \nu_{\mathrm{D}}$ はプロファイルの半值全幅であり以下の式で並進温度 $T$ と 関係付けられる ${ }^{21)}$.

$$
\Delta \nu_{\mathrm{D}}=2 \nu_{0} \sqrt{\frac{2 k_{\mathrm{B}} T}{m c^{2}} \ln 2}
$$

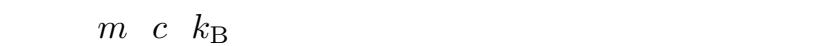
ン定数である.本研究では酸素原子の吸収ライン $777.19 \mathrm{~nm}$ を対象とした。

\section{3. 実 験 装 置}

第 3 図に測定系概略図を示す . 本システムでは波長可変 レーザー発振器として, 線幅 $300 \mathrm{~Hz}$ 以下の外部共振器付 半導体レーザー (Velocity Model 6300 , New Focus 社製) を用いた .レーザー振動数は吸収プロファイルを得るため， 变調周期 $1 \mathrm{~Hz}$, 变調幅 $30 \mathrm{GHz}$ で掃引した .レーザー飽和 強度 ${ }^{22)}$ で規格化したプローブレーザー強度は約 0.08 であ り，吸収飽和の影響は十分無視できる ${ }^{23)}$. 図中のアイソレー 夕は反射光が外部共振器に戻るのを防ぐために, エタロン (分解能 $1 \mathrm{GHz}$ ，ネオアーク社製）は波長計として用いた。 プローブ光は光ファイバにより真空チャンバ悹まで導か れ，コリメートレンズを経て真空チャンバ内に導入される． このレンズは 1 次元トラバース台に固定されており，気流 を半径方向にスキャンすることができる.プローブ光は測定 部で直径 $2 \mathrm{~mm}$ 程度にコリメートされており，プラズマか らの発光を除去するため気流から $3 \mathrm{~m}$ 離れた地点で非軸放 物型ミラーによりフォトディテクタ表面に集光される．フォ トディテクタにより検出したプローブ光はデジタルオシロ スコープ (NR-2000, Keyence 社製) により分解能 14 bit, サンプリング周波数 $20 \mathrm{kHz}$ で記録した .

第 4 図にIPG3 の気流写真および測定領域を示す . 測定 領域は IPG3 出口から下流 $130 \mathrm{~mm}$ の地点 $0<r<r_{\max }$

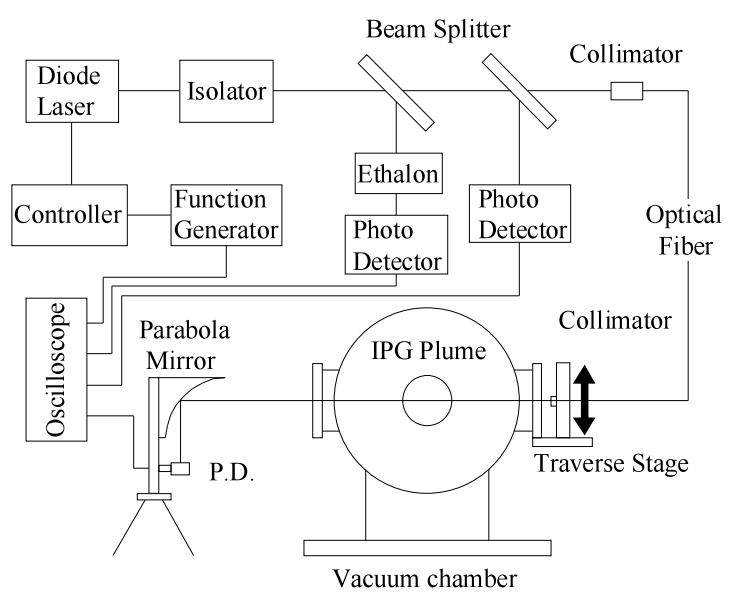

第3 図 測定系概略图 


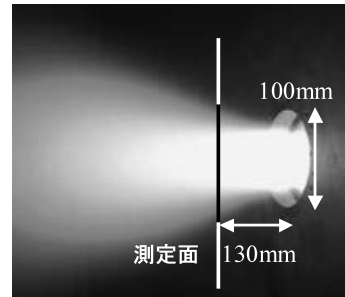

第4図 IPG3 気流

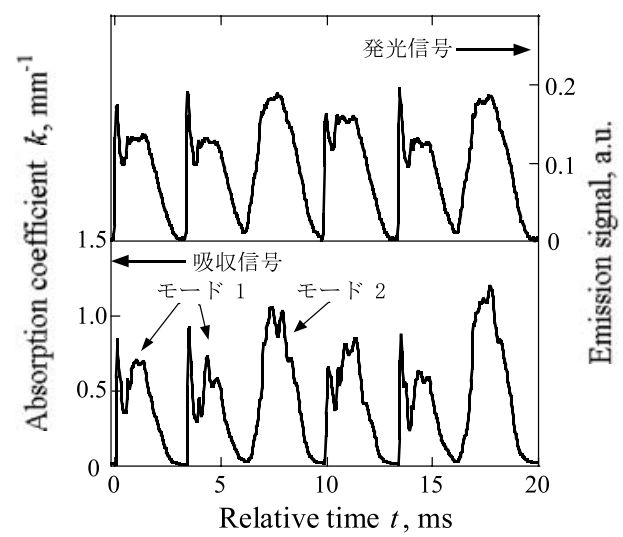

第 5 図 吸収および発光信号, $\nu=\nu_{0}-4 \mathrm{GHz}, r=0 \mathrm{~mm}$

である．ここで気流の諸特性は軸対称であると仮定し，半 径座標を $r$ とした . 本実験での作動条件は第 1 表と同じで あり，純酸素気流を対象とし， $r_{\max }$ は IPG3 出口径と同じ $50 \mathrm{~mm}$ である .

\section{4. 実 験 結 果}

第 5 図にプローブレーザー振動数固定下における吸収信 号およびプラズマ発光信号を示す. 図が示すように吸収信 号は発光信号に同期して周期 $\tau=3.3 \mathrm{~ms}$ で振動しているこ とがわかる. また, 吸収信号は周期 $\tau$ で咸少しているが 0 まで落ちることもあれば，乥うでない場合もある．弚れゆ え吸収信号は 2 つのモードに分類することができる．吸収 信号が 0 から増加し減少するものをモード 1 とし，この間 入力電力が最小時ではプラズマは消えていたと考えられる . 一方, 吸収信号が有限值から増加し減少するものをモード 2 とする.この間プラズマは常に維持されていたと考えら れる .

第 6 図に典型的なレーザー透過信号およびエタロン信号 を示す. 1 つの測定点に対しおよ年 $0.15 \mathrm{~s}$ 間 (約 40 サイク ル) の吸収信号を測定し, 解析した .

各モード, 時間での吸収プロファイルを得るため, 第 7 図 に示すように経過時間 $t=0.4 \mathrm{~ms}$ ごとに吸収係数を抽出し た .ここで各サイクルでの極小值を経過時間の原点 $t=0 \mathrm{~ms}$ とした . 第 8 図にアーベル变換前の各経過時間での吸収プ ロファイルを示す . このプロファイルをアーベル変換した 後得られた並進温度の時間履歴および発光信号を第 9 図に 示す. 図が示すように並進温度の時間履歴は発光信号の履

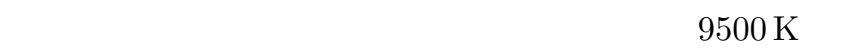

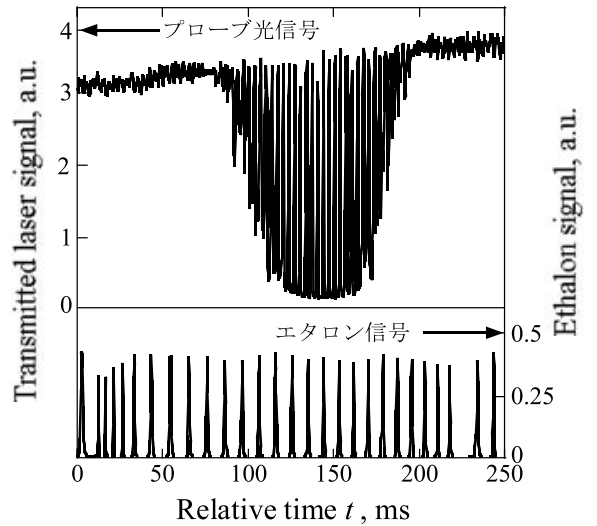

第 6 図

レーザー透過信号およびエタロン信号 , $r=0 \mathrm{~mm}$

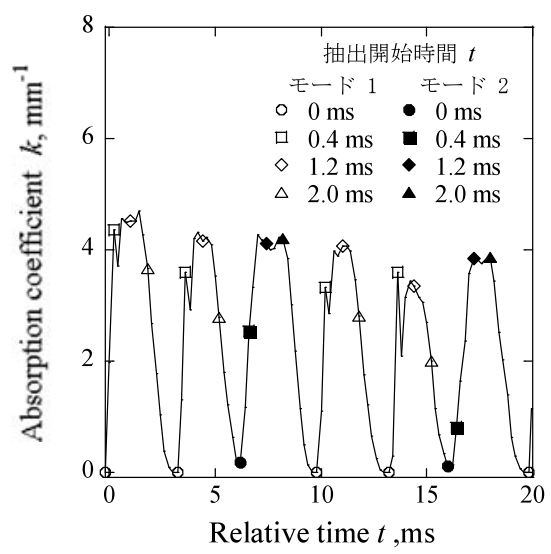

第 7 図 吸収係数および抽出点, $r=0 \mathrm{~mm}$

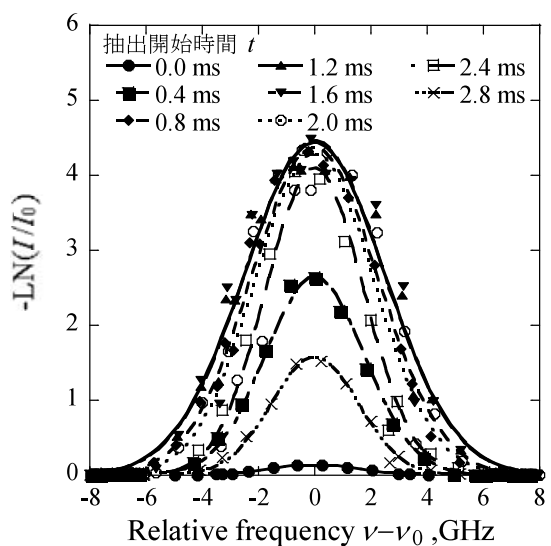

第 8 図 モード 1 における吸収プロファイルの時間変化, $r=0 \mathrm{~mm}$ ある

\section{5. 考察}

5.1 プラズマ特性の時間履歴 比全エンタルピー $h_{0}$ は 静的エンタルピー $C_{\mathrm{p}} T$, 化学ポテンシャル $h_{\mathrm{chem}}$, 運動エ ネルギー $u^{2} / 2$ の和であり, 以下の式で表される .

$$
h_{0}=C_{\mathrm{p}} T+h_{\text {chem }}+\frac{1}{2} u^{2}
$$

ここで， $C_{\mathrm{p}}$ は定圧比熱， $u$ は流速である . 


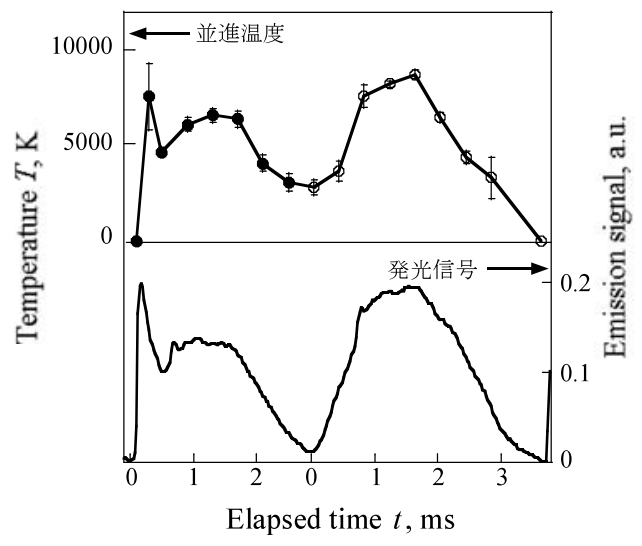

第 9 図 並進温度, 発光信号の時間履歴, $r=0 \mathrm{~mm}$

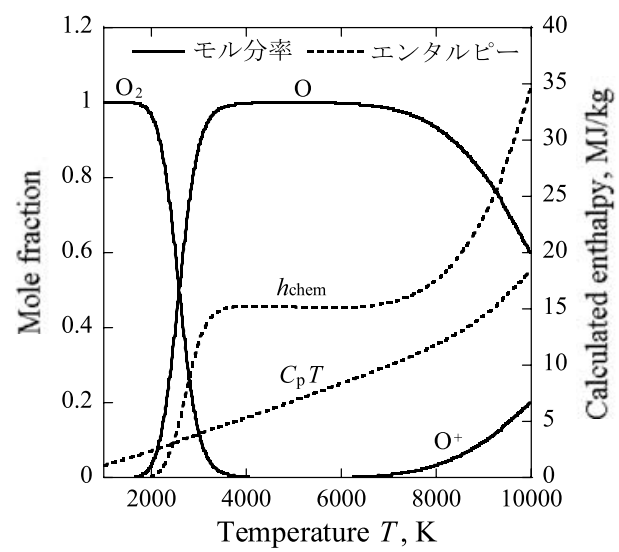

第 10 図 熱化学平衡条件下におけるエンタルピーおよび化学組成， $p_{\mathrm{amb}}=30 \mathrm{~Pa}$

本気流は低圧であるため熱化学非平衡にあると考えられ， 平衡であると仮定した場合, 電離度か実際よりも若干低く 見積もられる可能性があるが，エンタルピーの見積もりに 大きな影響はないと考えられる，従って，気流は熱化学平 衡にあると仮定し, 計測により得られた $T$ から $h_{0}$ およびモ ル分率を計算した .ここで 4 種の化学種 $\mathrm{O}_{2}, \mathrm{O}, \mathrm{O}^{+}, \mathrm{e}^{-}$ および, 2 つの化学反応 $\mathrm{O}_{2} \leftrightarrow 2 \mathrm{O}, \mathrm{O} \leftrightarrow \mathrm{O}^{+}+\mathrm{e}^{-}$を考慮し た . 平衡定数は文献 24)の値を用いた . 定圧比熱は各種の 定圧比熱にモル分率を考慮して計算した . 第 10 図に背圧 $p_{\mathrm{amb}}=30 \mathrm{~Pa}$ 下で計算したモル分率 , 静的エンタルピーお よび化学ポテンシャルの温度依存性を示す．

この結果を用いて第 11 図に気流軸上での各エンタルピー およびモル分率の時間履歴を示す . $h_{0}$ は最大 $86 \mathrm{MJ} / \mathrm{kg}$ に 達する.エンタルピーが最も高い時点では電離反応が盛ん になりイオンモル分率は $30 \%$ に達している .いずれにせよ 気流の酸素解離度は非常に高く，時間平均で $92 \%$ に達し， TPS 材の触媒性効果を正確に評価するのに役立つと考えら れる。

5.2 平均比全エンタルピー $\overline{\boldsymbol{h}}_{\mathbf{0}}(\boldsymbol{r}) \quad \bar{h}_{0}(r)$ は以下の式で 定義できる．

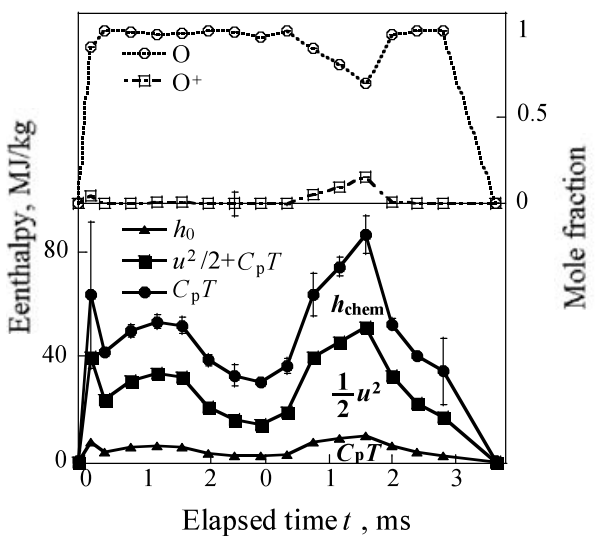

第11図 エンタルピー, モル分率の時間履歴, $r=0 \mathrm{~mm}$

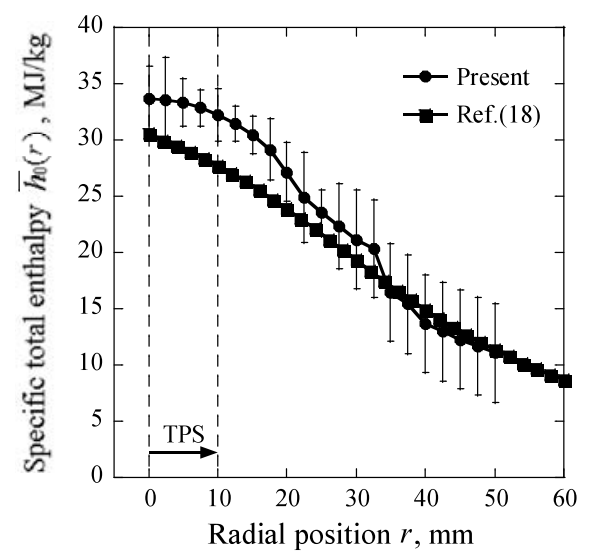

第 12 图 平均比エンタルピー分布

$\bar{h}_{0}(r)=\frac{\int_{0}^{\tau} h_{0}(r, t) \rho(r, t) u(r, t) \mathrm{d} t}{\int_{0}^{\tau} \rho(r, t) u(r, t) \mathrm{d} t}$.

ここで，

$$
\begin{aligned}
& \rho(r, t)=p_{\mathrm{amb}} / k_{\mathrm{B}} T(r, t), \\
& u(r, t)=M \sqrt{\gamma(T) R(T) T(r, t)}
\end{aligned}
$$

である $\gamma(T), R(T)$ は乥れ光れ比熱比，気体定数を示し 各温度に対し前節で述べた手法により計算し，マッハ数 $M$ は第 2 表の値を用いた .

第 12 図は測定領域での $\bar{h}_{0}(r)$ 分布を示す.最大値は気流 軸上で $33.7 \pm 2.9 \mathrm{MJ} / \mathrm{kg}$ であり，弚の分布は TPS プロー ブ面積 $(r<10.5 \mathrm{~mm})$ に対しほぼ一定である . 第 13 図は 軸上でのエネルギー収支を示す．これより化学ポテンシャ ルが全エンタルピーの $42.5 \%$ を占めていることがわかる .

5.3 計測結果の検証 本実験で得られたエンタルピーの 時間平均値を空間的に積分したものを過去に行ったプロー ブ測定の結果と比較することで本計測結果の妥当性を検証 する .

測定領域に入射する気流のプラズマ電力 $P_{\mathrm{plasma}, ~} r<r_{\max }$ および流量 $\dot{m}_{r<r_{\max }}$ は以下の式で表される . 


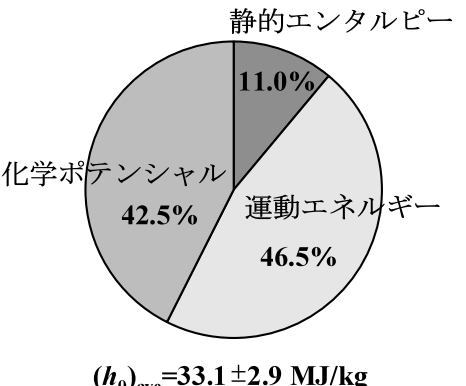

$\left(h_{0}\right)_{\mathrm{ave}}=33.1 \pm 2.9 \mathrm{MJ} / \mathrm{kg}$

第 13 図 エネルギー収支, $r=0 \mathrm{~mm}$

第 3 表 プラズマ電力 , 流量の比較

\begin{tabular}{|c|c|c|c|}
\hline Method & $r_{\max }$ & $P_{\text {plasma }}$ & $\dot{m}_{r}$ \\
\hline LAS (P & $50 \mathrm{~mm}$ & $17.5 \mathrm{~kW}$ & $0.86 \mathrm{~g} / \mathrm{s}$ \\
\hline カロリメータ & $60 \mathrm{~mm}$ & $28.2 \mathrm{~kW}$ & $3 \mathrm{~g} / \mathrm{s}$ (assumed) \\
\hline
\end{tabular}

\begin{tabular}{cc} 
第 4 表 & エンタルピーの比較 \\
\hline \multicolumn{1}{c}{ Method } & $\bar{h}_{0}(0)$ \\
\hline LAS (Present) & $33.7 \pm 2.9 \mathrm{MJ} / \mathrm{kg}$ \\
プローブ測定 $^{18)}$ & $30.5 \mathrm{MJ} / \mathrm{kg}$ \\
\hline
\end{tabular}

$$
\begin{aligned}
& P_{\text {plasma }, r<r_{\max }}=\int_{0}^{r_{\max }} 2 \pi r \rho(r) u(r) \bar{h}_{0}(r) \mathrm{d} r \\
& \dot{m}_{r<r_{\max }}=\int_{0}^{r_{\max }} 2 \pi r \rho(r) u(r) \mathrm{d} r
\end{aligned}
$$

本実験で得られる $P_{\text {plasma }, r<50 \mathrm{~mm}}$ をカロリメータによる 結果と比較したものを第 3 表に示す. 本実験で得られた $P_{\text {plasma }, r<50 \mathrm{~mm}}$ はカロリメータ測定での値より低い .これ は第 4 図にみられるように気流が $r>50 \mathrm{~mm}$ 領域に膨張 しているためだと考えられる . 同樣の理由で , 作動流量の 大半は低音の気流端 $(r>50 \mathrm{~mm})$ を流れていると考えら れる.

一方, 気流のエンタルピーに関しては文献 18) において $\bar{h}_{0}(r)$ 分布がプローブ測定により得られた熱流束密度 $\dot{q}(r)$, 全圧 $p_{0}(r)$ および $P_{\text {plasma }, r<r_{\text {max }}}$ により以下のPopeの式 ${ }^{25)}$ を用いて求められている.

$\bar{h}_{0}(r)=\frac{r_{\max }^{2}}{2} \frac{\dot{q}(r) / \sqrt{p_{0}(r)}}{\int_{0}^{r_{\max }}\left(\dot{q}(r) / \sqrt{p_{0}(r)}\right) r \mathrm{~d} r} \frac{P_{\text {plasma }, r<r_{\max }}}{\dot{m}_{r<r_{\max }}}$

ここで, $P_{\text {plasma, } r<r_{\max }}$ は $r_{\max }=60 \mathrm{~mm}$ 時の值である が流量は $\dot{m}_{r<r_{\max }}=\dot{m}=3 \mathrm{~g} / \mathrm{s}$ と仮定している. 第 12 図に本実験および文献 18$)$ の $\bar{h}_{0}(r)$, 第 4 表に軸上での值 $\bar{h}_{0}(0)$ を比較したものを示す. 両者の分布および軸上での 值とも良く一致し，本実験が妥当であることを示してい る. 本実験結果が文献值よりわずかに高いのは, プローブ 測定では $\dot{m}_{r<60 \mathrm{~mm}}$ が測定困難であるため, 全流量 $\dot{m}$ が $r<60 \mathrm{~mm}$ に流れ込むと仮定しているためであり，より正 確な $\dot{m}_{r<60 \mathrm{~mm}}$ の值を用いることでさらに本実験結果に近 づくものと考えられる.
6. ま と め

レーザー吸収分光法を用いて非定常な IPG3 気流診断を行 つた . 光の結果酸素原子の時間平均解離度は約 $92 \%$ であるこ とがわかった . また気流軸上では $\bar{h}_{0}(0)=33.7 \pm 2.9 \mathrm{MJ} / \mathrm{kg}$ と見積もられ，このうち $43 \%$ は化学ポテンシャルが占める. この結果はプローブ測定で得られた結果と良い一致を示す.

\section{考文 献}

1) Birkan, M. A.: Arcjets and Arc Heaters: An Overview of Research Status and Needs, J. Propul. Power, 12 (1996), pp. 1011-1017.

2) Milos, F. S.: Flowfield Analysis for High-Enthalpy Arc Heaters, J. Thermophys. Heat Transfer, 6 (1992), pp. 565568.

3) Auweter-Kurtz, M., Kurtz, H. L. and Laure, S.: Plasma Generators for Reentry Simulation, J. Propul. Power, 12 (1996), pp. 1053-1061.

4) Lago, V., Lebéhot, A., Dudeck, M., Pellerin, S., Renault, T. and Echegut, P.: Entry Conditions in Planetary Atmospheres: Emission Spectroscopy of Molecular Plasma Arcjets, J. Thermophys. Heat Transfer, 15 (2001), pp. 168-175.

5) Curry, D. M., Pham, V. T., Norman, I. and Chao, D. C.: Oxidation of Hypervelocity Impacted Reinforced Carbon, J. Spacecraft Rockets, 37 (2000), pp. 310-317.

6) Goulard, R.: On Catalytic Recombination Rates in Hypersonic Stagnation Heat Transfer, Jet Propul., 28 (1958), pp. 737-745.

7) Balat, M. and Berjoan, R.: Oxidation of Sintered Silicon Carbide under Microwave-Induced $\mathrm{CO}_{2}$ Plasma at High Temperature: Active-Passive Transition, J. Appl. Surface Sci., 161 (2000), pp. 434-442.

8) Bykova, N. G., Vasil'evskii, S. A., Gordeev, A. N., Kolesnikov, A. F., Pershin, I. S. and Yakushin, M. I.: Determination of the Effective Probabilities of Catalytic Reactions on the Surfaces on Heat Shield Materials in Dissociated Carbon Dioxide Flows, J. Fluid Dynam., 32 (1997), pp. 876-886.

9) Milos, F. S. and Shepard, C. E.: Thermal Analysis of an ArcHeater Electrode with a Rotating Arc Foot, J. Thermophys. Heat Transfer, 8 (1994), pp. 723-729.

10) Durgapal, P.: Electrode Phenomena in High-Current, HighPressure Arc Heaters, J. Thermophys. Heat Transfer, 7 (1993), pp. 412-417.

11) Herdrich, G., Auweter-Kurtz, M. and Kurtz, H.: New Inductively Heated Plasma Source for Reentry Simulations, J. Thermophys. Heat Transfer, 14 (2000), pp. 244-249.

12) Bottin, B., Varbonaro, M., Van der Haegen, V. and Paris, S.: Predicted and Measured Capability of the VKI 1.2 MW Plasmatron Regarding Re-Entry Simulation, ESA SP-426, 1998, pp. 553-560.

13) Gordeev, A. N.: Overview of Characteristics and Experiments in IPM Plasmatrons, VKI, RTO AVT/VKI Special Course on Measurement Techniques for High Enthalpy Plasma Flows, RTO EN-8, Rhode-Saint-Genese, 1999.

14) Herdrich, G., Auweter-Kurtz, M., Endlich, P. and Kurtz, H.: Mars Entry Simulation Using an Inductively Heated Plasma Generator, J. Propul. Power, 40 (2003), pp. 690-693.

15) Ito, I., Ishida, K., Mizuno, M., Sumi, T., Fujita, K., Nagai, J., Murata, H. and Matsuzaki, T.: Heating Tests of TPS Samples in $110 \mathrm{~kW}$ ICP-Heating Wind Tunnel, ISTS 2004-e20, 2004.

16) Yamada, T. and Inatani, Y.: Inductively-Coupled High Enthalpy Flow Generator for Planetary Entry Probes, ISTS 2004-e-21, 2004.

17) Herdrich, G., Auweter-Kurtz, M., Kurtz, H., Laux, T. and Winter, M.: Operational Behavior of Inductively Heated Plasma Source IPG3 for Entry Simulations, J. Thermophys. Heat Transfer, 16 (2002), pp. 440-449. 
18) Herdrich, G. and Auweter-Kurtz, M.: Development and Characterization of Inductively Heated Plasma Generator for Atmospheric Entry Simulations, AIAA Paper 2004-2503, 2004.

19) Baer, D. S., Nagali, V., Furlong, E., Hanson, R. K. and Newfield, M. E.: Scanned- and Fixed-Wavelength Absorption Diagnostics for Combustion Measurements Using Multiplexed Diode Lasers, AIAA J., 34 (1996), pp. 489-493.

20) Hanson, R. K.: Absorption Spectroscopy in Sooting Flames Using a Tunable Diode Laser, Appl. Opt., 19 (1980), pp. 482-484.

21) Matsui, M., Takayanagi, H., Oda, Y., Komurasaki, K. and Arakawa, Y.: Performance of Arcjet-Type Atomic-Oxygen Generator by Laser Absorption Spectroscopy and CFD Analysis, Vacuum, 73 (2004), pp. 341-346.
22) Bear, D. S. and Hanson, R. K.: Semiconductor Laser-Based Measurements of Quench Rates in an Atmospheric Pressure Plasma Using Saturated-Fluorescence Spectroscopy, Applied Optics, 32 (1993), pp. 948-955.

23) Matsui, M., Komurasaki, K. and Arakawa, Y.: Saturation Absorption in Laser Absorption Spectroscopy, AIAA Paper 2004-2597, 2004.

24) Guputa, R. N., Yos, J. M., Thompson, R. A. and Lee, K. P.: A Review of Reaction Rates and Thermodynamic and Transport Properties for an 11-Species Air Model for Chemical and Thermal Nonequilibrium Calculations to $30000 \mathrm{~K}$, NASA Reference Publication 1232, 1990.

25) Marvin, J. G. and Pope, R. B.: Laminar Convective Heating and Ablation in the Mars Atmosphere, AIAA J., 5 (1967), pp. $240-248$. 